Journal of Life Economics

Cilt / Volume 7, Say1 / Issue 2, 2020, pp. 161-176

E - ISSN: 2148-4139

URL: https://www.ratingacademy.com.tr/ojs/index.php/jlecon

DOİ: https://doi.org/10.15637/jlecon.7.011

Araştırma Makalesi/Research Article

\title{
BIST 100 DE YER ALAN ANA METAL SANAYI FİRMALARININ VERİ ZARFLAMA ANALİZi İLE PERFORMANS ÖLÇÜMÜ ${ }^{1}$
}

\author{
DATA PERFORMANCE MEASUREMENT OF MAIN METAL INDUSTRY \\ COMPANIES IN BIST 100 WITH DATA ENVELOPMENT ANALYSIS
}

\author{
Ümran ŞENGÜL* \\ * Doç. Dr. Çanakkale Onsekiz Mart Üniversitesi, Siyasal Bilgiler Fakültesi, \\ Çanakkale/TÜRKIYE, e-mail: umransengul@comu.edu.tr \\ ORCID: https://orcid.org/0000-0001-5867-863X
}

Geliş Tarihi: 13 Ocak 2020; Kabul Tarihi: 15 Nisan 2020

Received: 13 January 2020; Accepted: 15 April 2020

\begin{abstract}
$\ddot{O Z Z T T}$
Ana Metal Sanayi, ülke ekonomisinin ve sanayisinin gelişmesinde önemli bir faktör olmakla birlikte, kriz dönemlerinde sektörün küçülmesi, ülke istihdamını ve ekonomisinin negatif yönde etkilemektedir. Ana Metal Sanayi firmalarının yıllar bazında performans değerlendirmesinin yapılması, bu çalışmanın ana amacını oluşturmaktadır. Performans değerlendirmesi, işletmenin kullandı̆ kaynakları, ürettiği mal ve hizmetleri, elde ettiği sonuçları takip etmesi, düzenli ve sistematik bir şekilde veri toplaması, bunları analiz edip yorumlamast ve raporlaması sürecidir. Performansin hesaplanması ve ölçülmesi; zor ve karmaşı bir süreçtir. Firma düzeyinde ve sektör bazındaki finansal değerlendirmeler firmaların performans değerlendirmesinde yatırımcllar ve firma yöneticileri açısından yol göstericidir. Ancak finansal oranları girdi ve çıktı değişkeni olarak değerlendirip, firmanın performans değerlendirilmesinin yapılması daha gerçekçi yorumlar yapılmasını sağlar. Bu çalışmada, BIST'te işlem gören 17 adet Ana Metal Sanayii firmalarının etkinliği 2010-2018 dönemi için Veri Zarflama Analiz Yöntemi (VZA) kullanılarak analiz edilmiştir. Çalışmada, girdi değişkenleri; Likidite oranı, Cari oran, Toplam Borç/Özsermaye, Toplam Aktifler; Çıktı değişkenleri; Net Gelir, Özkaynak Karlılığl, Net Kar Marjı, Tobin Q'dur. Çalışmada, girdiye yönelik etkinlik analizi yapılmıştır ve analiz sonucuna göre, 2010-2018 döneminde etkinlik skorlarl, ilgili bütün firmaların yılllk ortalama değerleri; CCR ve BCC modeline göre 2012 yllından 2018 yllına kadar genel bir düşüş trendi göstermektedir. 2018 yılında 2016-2017 yıllarına göre bir parça pozitifyöne dönüş trendi göstermesine rağmen 2012 yllından daha düşük seviyede olduğu görülmüşürr.
\end{abstract}

Anahtar Kelimeler: Metal Ana Sanayi, Finansal Performans, Veri Zarflama Analizi

Jel Kodları: L25, D 61, L61. 


\begin{abstract}
Although Main Metal Industry is an important factor in the development of the country's economy and industry, the shrinkage of the sector during crisis periods negatively affects the employment and economy of the country. The main purpose of this study is to evaluate the performance of Main Metal Industry companies on a yearly basis. Performance evaluation is the process of monitoring the resources used by the enterprise, the goods and services produced, the results obtained, and collecting data in a regular and systematic way, analyzing, interpreting and reporting them. Calculation and measurement of performance; is a difficult and complex process. Firm-level and sectorbased financial evaluations guide the performance evaluation of firms for investors and managers. However, evaluating the financial ratios as input and output variables and evaluating the performance of the firm provide more realistic interpretations. In this study, the effectiveness of 17 Main Metal Industry companies traded in BIST was analyzed using Data Envelopment Analysis Method (DEA) for the period of 2010-2018. In the study, input variables; Liquidity ratio, Current ratio, Total Debt / Equity, Total Assets; Output variables; Net Income, Return on Equity, Net Profit Margin, Tobin Q. Entryoriented activity analysis was conducted and according to the results of the analysis, activity scores in 2010-2018 period, annual average values of all relevant companies; According to CCR and BCC models, it shows a general downward trend from 2012 to 2018. Although it showed a slightly positive trend in 2018 compared to 2016-2017, it was found to be lower than 2012.
\end{abstract}

Keywords: Main Metal Industry, Financial Performance, Data Envelopment Analysis

JEL Codes: L25, D 61, L61

\title{
1. GÍRIŞ
}

Milli gelir içerisinde büyük paya sahip olan imalat sanayi, ülkemizin ekonomik büyümesinde en önemli sektörlerden biridir. İmalat sanayinin bir kolu olan ana metal sanayi de ülke ekonomisi için anahtar bir role sahiptir ve ülke sanayisinin gelişmesinde güdüleyici faktörlerden biridir. Enerji, kimya, inşaat ve otomotiv olmak üzere birçok sektörde kullanım alanı olan ana metal sanayi özellikle demir-çelik alanındaki yatırımları önemlidir. TUİK ana metal sanayi firmalarını ISIC Rev3 adı altında sınıflamaktadır. Bu sınıflamaya göre, ana metal sanayi firmaları; demir-çelik ana sanayi ve demir-çelik dışındaki ana metal sanayi (kurşun, metal, kalay, alüminyum, bakır, çinko ve demir dışındaki diğer metaller) alt sektörlerinden oluşmaktadır (Özden ve Haçikoğlu, 2017). Türk çelik sektörü 2018 yılı üretimi 37,3 milyon ton olmuştur. 2019 yılı ilk 4 aylık verilerine göre üretim ve ihracat rakamlarında düşüş gözlemlenmiştir. Ülkemizde üretilen ve ihracatı yapılan profil, boru ve bağlantı elemanları, nervürlü demir, yuvarlak demir ve sac'1n birim fiyatları 650-890 \$/ton arasındadır. Ancak ihtal edilen, paslanmaz çelik ve süper alaşımlı çeliklerin birim fiyatları ise $2.500 \$ /$ ton- $10.000 \$ /$ ton düzeyi arasında seyretmektedir. Paslanmaz ve nitelikli çelik yatırımları, demir çelik sanayisinin yüksek teknolojiye geçiş sürecinde büyük önem taşımaktadır (Demir Çelik Sektörü Raporu, 2019).

Firmaların performanslarının ölçülmesi firma sahipleri, yatırımcılar ve kullanıcılar için önemlidir. Demir-çelik sektörü, diğer sektörlere girdi sağlayan lokomotif bir sektördür. Bu açıdan ana metal sanayi firmalarının etkin olarak faaliyet göstermesi, ülke ekonomisini de doğrudan etkileyen bir etkendir. Kaynakların sınırlı olması, işletmelerin her zaman etkinlik ve verimlilik konularına önem vermesine sebep olmuştur. Firmaların kaynaklarını optimal kullanmaları rekabet edebilme güçlerini de arttırmaktadır. Etkinlik ölçümleri, firmaların ulusal ve uluslararası piyasalarda rekabet edebilmesini sağlayacak önemli bir husustur. 
Firmaların, ulusal ve uluslararası piyasalarda rekabet edebilme güçlerinin korunabilmesi için güçlü bir finansal yapıya sahip olmaları gerekmektedir. Çalışmada, firmaların etkinliklerini ölçebilmek için, sektör içerisinde ve yıllar bazında finansal rasyo değerleri değişken olarak kullanılmaktadır. Literatürde, firmaların finansal açıdan etkinliklerini ölçmede, yöntem olarak, parametrik olmayan Veri Zarflama Analiz (VZA) çok sık kullanılmaktadır. VZA birden çok girdi ve çıktı dikkate alındığında etkinlik ölçmede kullanılan doğrusal programla modellerinden biridir ve bir çok modeli vardır.

Literatürde VZA'ni kullanılarak, imalat sanayi firmalarının etkinliklerini ölçen çalışmalardan bazıları şunlardır. Mahadevan(2002), 1981-1996 yıllarında Malezya' da imalat sektörlerinde 28 endüstri firmasının etkinliğini, VZA ile hesaplamıştır. Destefanis ve Sena (2007), İtalya'da yer alan imalat firmalarının, teknik etkinliğini VZA ile hesaplamışlardır. Şirket ortaklığ karakteristiklerinden bazılarının teknik etkinliği pozitif yönde etkilediğini bulmuşlardır. Yıldız (2007), İMKB'de yer alan 105 imalat sanayi şirketinin etkinliğini 2005 yılı için hesaplamıştır. Çalışma sonucunda, şirketlerin \%70 nin etkin olduğunu bulmuştur. Ertuğrul ve Işık (2008), IMKB'de yer alan 13 metal ana sanayi işletmesinin 2003-2007 dönemleri mali tablolarını dikkate alarak, firma etkinliklerini VZA ile hesaplamışlardır. Girdi değişkenleri olarak; aktif ve özsermaye, çıktı değişkenleri olarak, net satışlar ve net karı almışlardır. Liu ve Wang(2009), imalat sektörü firmalarının verimliliklerini VZA ile hesaplamışlardır. Yalama ve Sayım, (2008), IMKB'de yer alan imalat sanayi firmalarının etkinliğini VZA yöntemi ile hesaplamışlardır. Ata ve Yakut (2009), 1996-2006 dönemi itibariyle, Türkiye'de imalat sektöründe yer alan firmaların etkinliğini VZA ile hesaplamışlardır. Aslan, (2009), İMKB ana metal sanayi endeksine kote olmuş, 13 firmanın etkinliğini VZA yöntemi ile ölçmüştür. Altın (2010), IMMKB sınai şirketlerine yönelik olarak 142 şirketin mali etkinliğini VZA yöntemi ile hesaplamıştır. Arığ (2011), İMKB de kote olmuş 149 imalat sanayi firmasının 2009 yılı finansal rasyo değerlerini kullanılarak VZA yöntemi ile etkinlik analizini yapmıştır. Cenger (2011), BIST de işlem gören çimento şirketlerinin, 2003 yılı etkinlik ölçümlerini CCR ve BBC yöntemlerine göre yapıp, sonuçlarını karşılaştırmıştır. Tosunoğlu ve Uysal (2012), 2009 yılı içerisinde, İMKB'de işlem gören ve İSO 500'de yer alan 29 adet yabancı sermaye payına sahip firmanın etkinliğini VZA ile yapmışlardır. 8 firmanın etkin 21 firmanın etkin olmadığı sonuca varmışlardır. Yayar ve Çoban (2012), İSO 500'e giren dokuma ve giyim eşya sanayiinde faaliyet gösteren firmaların 2008-2010 dönemi etkinliklerini VZA ile ölçmüşlerdir. VZA analizlerinde CCR ve BCC yi kullanmışlarıdır. Orçun vd. (2014), İMKB 100'de yer alan 25 imalat sanayi şirketinin 2008 kriz öncesi ve sonrasındaki döneme ilişkin etkinlik düzeylerini VZA ile hesaplamışlardır. Bakırcı vd., (2014), BIST'de yer alan, Demir Çelik Metal Ana Sanayi sektöründeki 14 firmanın 2009-2011 yıllarına ait finansal performanslarını VZA yöntemi ile hesaplamışlardır. Özkan ve Bircan (2015), Suşehri küçük sanayii sitesinde bulunan oto-tamircisi firmaların etkinliklerini VZA ile hesaplamışlardır. Model olarak, CCR ve BCC modellerini kullanmışlardır. Özek (2015), Borsa İstanbul'da işlem gören imalat firmalarının, 2005-2013 yılları kapsamında etkinliklerini VZA kullanarak hesaplamıştır. Model olarak CCR ve BCC modellerini kullanmıştır. Çıtak ve İltaş (2017), 20132015 döneminde, Borsa İstanbul Teknoloji Endeksi'nde yer alan firmaların etkinliklerini ölçmek için VZA'nin BCC ve CCR modellerini kullanmışlardır. Tutkavul (2019), BIST-SINAİ endeksinde işlem gören imalat işletmelerinin 2012-2016 yılları arasında finansal etkinlik ve verimlilik ölçümünü yapmışlardır.

Çalışmada VZA yöntemlerinden, girdi yönelimli CCR ve BCC modeline göre firmaların etkinlikleri ölçülmüştür. Girdi yönelimi modellerde, amaç minimum girdi ile maksimum çıktı elde etmektir. Bu amaçla model kurulmuş, 2010-2018 yılları için BIST 100 de yer alan 17 Ana Metal Sanayi firmasının etkinliği ölçülmüştür. 2018 yılı için girdi ve çıktı değişkenlerinin değerlendirilmesi yapılmış ve 2010-2018 döneminde firmaların etkinliği grafikler ile 
tartışılmıştır. Literatürde, ana metal sanayii firmalarının finansal performanslarını ölçmek için sınırlı sayıda yapılan çalışma vardır. Bu çalışmada, literatürde finansal performansı ölçmek için en sık kullanılan kriterlerin yanında, önceki çalışmalarda kullanılmayan ve firmaların entelektüel varlığını ölçen Tobin Q değerleride dikkate alınmıştır

Çalışmanın bundan sonraki kısımları, metodoloji, uygulama ve sonuç olarak devam etmektedir.

\section{METODOLOJI}

Veri zarflama analizi (VZA), çok sayıda çıktı ve girdi değişkenlerini kullanarak, firmaların etkinlik performanslarının hesaplanmasında kullanılan parametrik olmayan doğrusal programlama temelli bir yöntemdir. VZA, girdi ve çıktı değişkenlerinin çok olduğu durumlarda Karar Verme Birimlerinin (KVB) kıyaslanması zorlaştığından, KVB'nin göreli etkinliklerini ölçer. VZA'da etkinlik ölçümü için, işletmelerin benzer stratejik hedeflere sahip olması yani girdi ve çıktılarının aynı tür olması gerekmektedir.

VZA nın ilk modeli Charnes Cooper Rhodes-CCR modeli ölçeğe göre sabit getiri varsayımı altında etkinliği ölçmektedir. Model girdi ve çıktı yönelimli olmak üzere iki tane tanımlanabilir.

Girdi yönlü CCR modelinde $\Theta^{*}$ etkinlik skoru olmak üzere,

$\Theta^{*}=1$ ve artıklar sıfırsa bu karar verme birimi etkindir.

$\Theta^{*}<1$ ise bu karar verme birimi etkin değildir.

Çıktı yönlü CCR modelinde,

$\Theta^{*}=1$ ve artıklar sıfirsa bu karar verme birimi etkindir.

$\Theta^{*}>1$ ise bu karar verme birimi etkin değildir (Cooper vd., 2007).

Girdi yönelimli VZA modellerinde, çıktı bileşimini en etkin üretebilecek, en uygun girdi bileşimini bulmak için kullanılır. Çıktıya yönelimli VZA modellerinde ise, belirli bir girdi bileşimi için en fazla ne kadar çıktı bileşimi elde edilebileceğini bulmak için kullanılır (Yeşilyurt, 2003). VZA modellerinin, primal ve dual durumundaki formülasyonları aşağıda verilmiştir (Charnes vd., 1994). Modellerde, $s$ çıktı sayısını, $m$ girdi sayısını, $n$ karar verme birimi sayısını göstermektedir.

\section{Girdi yönlü primal ve dual CCR modelleri}

\section{Primal Model:}

$\operatorname{Min} \theta$

$\sum_{j=1}^{n} \lambda_{j} x_{i j}-\theta x_{i 0} \leq 0$

$\sum_{j=1}^{n} \lambda_{j} y_{r j}-\theta x_{r 0} \geq 0$

$\lambda_{j} \geq 0$ 


\section{Dual Model}

$\operatorname{Max} \sum_{r=1}^{s} u_{r} y_{r 0}$

$\sum_{i=1}^{m} v_{i} x_{i 0}=1$

$\sum_{r=1}^{s} u_{r} y_{r j}-\sum_{i=1}^{m} v_{i} x_{i j} \leq 0 \quad, \quad j=1, \ldots, n, \quad u_{r} \geq 0, \quad v_{i} \geq 0$

\section{Çıktı yönlü primal ve dual CCR modelleri}

$\operatorname{Max} \theta$

$\sum_{j=1}^{n} \lambda_{j} x_{i j}-x_{i 0} \leq 0$

$\sum_{j=1}^{n} \lambda_{j} y_{r j}-\theta y_{r 0} \geq 0$

$\lambda_{j} \geq 0$

\section{Dual Model}

$\operatorname{Min} \sum_{r=1}^{s} v_{i} x_{i 0}$

$\sum_{i=1}^{s} u_{r} y_{r j}=1 \quad, \quad r=1, \ldots, s$

$\sum_{r=1}^{s} u_{r} y_{r j}-\sum_{i=1}^{m} v_{i} x_{i j} \leq 0 \quad, \quad j=1, \ldots, n, \quad u_{r} \geq 0, \quad v_{i} \geq 0$

Bu primal ve dual modellerde,

$x_{i j}$ : $j$. karar verme biriminin kullandığı $i$. girdi miktarı

$y_{r j}: j$. karar verme birimi tarafından üretilen $r$. çıktı miktarı

$x_{i 0}$ : sıfırınc1 karar verme biriminin kullandığ 1 . girdi miktarı

$y_{r 0}$ : sıfırıncı karar verme birimi tarafından üretilen $r$. çıktı miktarı

$u_{r}$ : sıfırıncı karar verme birimi tarafından $r$. çıktıya verilen ağırlık

$v_{i}$ : sıfırıncı karar verme birimi tarafından $i$. girdiye verilen ağırlıktır. 
CCR modelleri karar verme birimlerinin etkinliğini ölçeğe göre sabit getiri altında ölçmektedir. Ölçeğe göre sabit getiri (Constant Returns to Scale-CRS) sistemin girdisinde yapılan artışın, çıktısında da aynı oranda artış göstermesi anlamına gelir. Banker vd. (1984) tarafindan önerilen Banker Charnes Cooper-BCC modeli, ölçeğe göre değişken getiri altında KVB lerinin etkinliğini ölçmektedir. Ölçeğe göre değişken getiri (Variable Returns to ScaleVRS), girdilerdeki artış miktarına karşılık, çıktılarda daha az ya da daha çok artış görülebilmesidir.

$\Theta^{*}$ etkinlik skoru olmak üzere,

\section{Girdi yönlü BCC modelinde}

$\Theta^{*}=1$ ise ve artıklar sıfırsa bu karar verme birimi etkindir.

$\Theta^{*}<1$ ise bu karar verme birimi etkin değildir.

\section{Çıktı yönlü BCC modelinde ise,}

$\Theta^{*}=1$ ise ve artıklar sıfirsa bu karar verme birimi etkindir.

$\Theta^{*}>1$ ise bu karar verme birimi etkin değildir (Cooper vd., 2007).

Aşağıda ilgili modeller verilmiştir.

\section{Girdi yönlü primal ve dual BCC modelleri}

\section{Primal Model:}

$\operatorname{Min} \theta$

$\sum_{j=1}^{n} \lambda_{j} x_{i j}-\theta x_{i 0} \leq 0$

$\sum_{j=1}^{n} \lambda_{j} y_{r j}-y_{r 0} \geq 0$

$\sum_{j=1}^{n} \lambda_{j}=1 \quad, \quad \lambda_{j} \geq 0$

\section{Dual Model}
$\operatorname{Max} \sum_{r=1}^{s} u_{r} y_{r 0}-u_{0}$
$u_{r} \geq 0$
$\sum_{i=1}^{s} v_{i} x_{i 0}=1$,
$v_{i} \geq 0$
$\sum_{r=1}^{s} u_{r} y_{r j}-\sum_{i=1}^{m} v_{i} x_{i j} \leq 0$
$j=1, \ldots, n$, 


\section{Çıktı yönlü primal ve dual BCC modelleri}

$\operatorname{Max} \theta$

$$
\begin{gathered}
\sum_{j=1}^{n} \lambda_{j} x_{i j}-x_{i 0} \leq 0, \\
\sum_{j=1}^{n} \lambda_{j} y_{r j}-\theta y_{r 0} \geq 0, \\
\sum_{j=1}^{s} \lambda_{j}=1
\end{gathered}
$$

\section{Dual Model}

$$
\begin{aligned}
& \operatorname{Min} \sum_{r=1}^{s} v_{i} x_{i 0} \\
& \sum_{i=1}^{s} u_{r} y_{r j}=1, \quad r=1, \ldots, s \\
& \sum_{r=1}^{s} u_{r} y_{r j}-\sum_{i=1}^{m} v_{i} x_{i j}-v_{0} \leq 0 \quad, \quad j=1, \ldots, n, \quad u_{r} \geq 0, v_{i} \geq 0
\end{aligned}
$$

şeklindedir.

\section{UYGULAMA}

Çalışma BIST 100'de yer alan ana metal sanayi firmaları için yapılmıştır. Kamu aydınlatma platformunun internet sitesinden alınan bilgilere göre, BIST 100'de 17 adet ana metal sanayi firmas1 mevcuttur (https://www.kap.org.tr/tr/bist-sirketler). Bu firmalar; DOKTA BRSAN, IZMDC, BURVA, BURCE, CELHA, CEMAS, CUSAN, DMSAS, CEMTS, ERBOS, EREGL, ISDMR, KRDMA, OZBAL, SARKY ve TUCLK'dir.

Literatürden firmaların etkinliğini ölçmek için kullanılan finansal rasyolar incelenmiştir. Literatürde firmaların finansal performansını ölçmek için en sık kullanılan girdi değişkenleri; Cari oran, Likidite oranı, Toplam Borç/Özsermaye, Kısa Vadeli Borç/Toplam Aktifler, Toplam Aktifler; Çıktı değişkenleri; Net Kar Marjı, Özkaynak Karlılı̆̆ı, Net Gelir/Aktifler'dir. Çalışma da, ana metal sanayi firmalarının performansını ölçmede kullanılmayan Tobin Q değeri de dikkate alınmıştır. TobinQ oranı 1'den yüksek çıkarsa, işletmenin yüksek değerde entelektüel varlığa sahip olduğu ve böylece, varlıklardan yüksek getiriler elde ettiği, anlamına gelmektedir. VZA analizinde girdi ve çıktı değişkenleri arasındaki ilişkinin yüksek olmaması modelin doğru sonuç çıkarması açısından önemlidir. Bu açıdan değişkenler arasındaki ilişkiye yani korelasyonuna bakılmıştır. Tablo 1'de değişkenler arasındaki korelasyon değerleri verilmiştir. 
Tablo 1: Girdi ve Çıktı değişkenleri arasında korelasyon değerleri

\begin{tabular}{llllllllll}
\hline & CO & LO & TBOZ & TAKT & KVB & NKM & OKK & NGA & T \\
\hline CO & 1 & & & & & & & \\
LO &,$- 363 *$ & 1 & & & & & & & \\
TBOZ & 0,031958 & 0,088762 & 1 & & & & & & \\
TAKT & $-0,067$ & 0,185276 &,$- 364 *$ & 1 & & & & & \\
KVB &,$- 780^{* *}$ & $-0,1541$ &, $681 * *$ &,$- 395 *$ & 1 & & & & \\
NKM & $-0,0755$ & 0,178695 & 0,034418 & $-0,0354$ & 0,15358 & 1 & & & \\
OKK & 0,227531 & 0,10625 & 0,144649 & $-0,27359$ & 0,099902 & 0,093308 & 1 & & \\
NGA & 0,141691 & $-0,10864$ & 0,191622 & $-0,19288$ & $-0,03432$ &,$- 348 *$ & 0,131762 & 1 & \\
T & $-0,10437$ &, $330 *$ & $-0,03224$ & 0,139081 & 0,081766 & $-0,02315$ & 0,177775 &,$- 481 * *$ & 1 \\
\hline
\end{tabular}

Korelasyon değerlerine bakıldığında, Kısa Vadeli Borçlar ile Cari Oran arasında yüksek korelasyon olduğundan Kısa vadeli borçlar değişkeni girdi değişkenleri içinden çıkılmıştır. Çalışmada kullanılan girdi ve çıktı değişkenlerinin son hali Tablo 2'de verilmiştir.

Tablo 2: Çalışmada kullanılan girdi-çıktı değişkenleri

\begin{tabular}{cc}
\hline Girdi Değişkenleri & Çıktı Değişkenleri \\
\hline Cari Oran-CO & Net Kar Marjı-NKM \\
Likidite (Asit-Test Oranı) Oranı-LO & Özkaynak Karlılığı-OKK \\
Toplam Borç/Özsermaye- TBOZ & Net Gelir -NG \\
Toplam Aktifler- TAKT & TobinQ-T \\
\hline
\end{tabular}

VZA analizlerinde modelin doğru bir şekilde çalışabilmesi için, karar verme birimlerinin sayısı, girdi ve çıtı değişken sayılarının toplamının iki katı olmalıdır (Cooper vd, 2000). Bu çalışmada girdi ve çıktı değişkenlerinin sayılarının toplam 8 dir. O halde karar verme sayısının yaklaşık 16 olması gerekir. Ayrıca değişken değerlerinin negatif olmaması gerekir. Yukardaki modellere dikkate edilirse son kısıt tüm değişken değerlerinin pozitif olması kısıtıdır. Bu açıdan negatif değer alan değişken değerleri pozitif olacak şekilde sayı eklenmiş ve bu sayı o değişkene ait tüm değerler eklenmiştir. Modellerin çözümünde, EMS 1.3.0 paket programı kullanılmıştır. Çalışmaya ait veriler FINNET'ten temin edilmiştir.

Aşağıda 2018 yılına ait hesaplamalar verilmiştir.

Çalışmada kullanılan Girdi-Çıktı değişkenlerinin 2018 yılına ait verileri imalat sanayi firmaları bazında Tablo 3 'de verilmiştir. 
Tablo 3: Etkinlik ölçmek için kullanılan değişken değerleri (2018 Y1lı)

\begin{tabular}{|c|c|c|c|c|c|c|c|c|}
\hline \multirow[t]{2}{*}{ KVB } & \multicolumn{4}{|c|}{ GÍRDİ DEĞİŞKENLERİ } & \multicolumn{4}{|c|}{ ÇIKTI DEĞİŞKENLERİ } \\
\hline & $\mathrm{CO}$ & LO & TBOZ & TAKT & NKM & OKK & NGA & TobinQ \\
\hline BRSAN & 1,1 & 0,71 & 146,32 & 6824019354 & 5,8 & 2769497690 & 283224164 & 0,78 \\
\hline BURCE & ,92 & 0,44 & 159,22 & 89214316 & 0,28 & 33356747 & 229400 & 0,91 \\
\hline BURVA & 1,73 & 0,8 & 172,12 & 3666976 & 0,49 & 5022324 & 81080 & 1,3 \\
\hline CELHA & 0,99 & 0,53 & 276,01 & 206562186 & 5,89 & 54935200 & 18372631 & 1,23 \\
\hline CEMAS & 1,48 & 1,3 & 169,18 & 35229870 & $-18,08$ & 126665139 & 32174264 & 2,98 \\
\hline CEMTS & 4,45 & 2,34 & 25,08 & 534735170 & 19,13 & 427516859 & 146269830 & 1,58 \\
\hline CUSAN & 1,39 & 0,86 & 120,38 & 327015237 & $-0,2$ & 144441985 & -5059369 & 0,99 \\
\hline DMSAS & 1,6 & 1,18 & 158,4 & 310381321 & & 120117247 & 36157657 & 1,17 \\
\hline DOKTA & 0,54 & 0,28 & 955,01 & 1359736303 & & 3583 & 101230873 & $1,3 \xi$ \\
\hline ERBOS & 2,28 & 1,58 &, 53 & 62 & & 188 & 2002031 & 1,13 \\
\hline EREGL & 2,85 & 1,68 & 44,16 & 10000 & & 1000 & $45 \mathrm{E}+09$ & 1,18 \\
\hline ISDMR & 3,36 & 2,02 & 33,4 & 20981564000 & 25,87 & 15727768000 & $4,109 \mathrm{E}+09$ & 1,34 \\
\hline IZMDC & 0,58 & 0,2 & 1021,99 & 3395540806 & $-7,32$ & 301262274 & $-3,62 E+08$ & 1,2 \\
\hline OZBAL & 0,39 & 0,34 & 14374,79 & 96303953 & $-12,75$ & 665322 & 0 & 1,41 \\
\hline SARKY & 1,3 & 0,84 & 225,4 & 1792008888 & 1,61 & 550557406 & 91217033 & 1,08 \\
\hline TUCLK & 1,09 & 0,92 & 146,77 & 219943001 & $-4,05$ & 89129586 & -6340889 & 0,9 \\
\hline
\end{tabular}

Tablo 4'de, 2018 yılına ait, Girdi yönlü CCR ve BCC modellerin çözüm değerleri verilmiştir.

Tablo 4: 2018 yılı BIST 100 de yer alan Ana Metal Sanayi Firmalarının Girdi Yönlü CCR model etkinlik skorları

\begin{tabular}{|l|l|l|l|}
\hline KVB & Score & Benchmarks & Refarans alınma sayısı \\
\hline BRSAN & $87,14 \%$ & $4(0,54) 8(0,12) 12(0,17)$ & \\
\hline BURCE & $100,00 \%$ & & 5 \\
\hline BURVA & $100,00 \%$ & & 1 \\
\hline CELHA & $94,02 \%$ & & 2 \\
\hline CEMAS & $100,00 \%$ & & 3 \\
\hline CEMTS & $100,00 \%$ & & 3 \\
\hline CUSAN & $84,46 \%$ & $2(0,70) 5(0,04) 6(0,16)$ & \\
\hline DMSAS & $91,48 \%$ & $2(1,11) 11(0,01) 14(0,04)$ & 1 \\
\hline DOKTA & $100,00 \%$ & & 1 \\
\hline ERBOS & $100,00 \%$ & & 1 \\
\hline EREGL & $100,00 \%$ & & 5 \\
\hline ISDMR & $100,00 \%$ & & \\
\hline IZMDC & $84,66 \%$ & $9(0,83) 11(0,01) 14(0,04)$ & 2 \\
\hline OZBAL & $100,00 \%$ & & $2(0,72) 4(0,21) 5(0,04) 12(0,03)$ \\
\hline SARKY & $62,41 \%$ & & \\
\hline TUCLK & $83,99 \%$ & $2(0,84) 3(0,05) 6(0,04)$ & \\
\hline
\end{tabular}


Tablo 4'de etkin olan karar birimleri, BURCE, BURVA, CEMAS, CEMTS, DOKTA, ERBOS, EREGL, ISDMR ve OZBAL dır. BURCE ve ISDMR diğer firmalar tarafından $5 \mathrm{kez}$, CEMAS ve CEMTS $3 \mathrm{kez}$, CELHA, ve OZBAL $2 \mathrm{kez}$ ve BURVA, DOKTA, ERBOS ve EREGL 1 kez referans alınmıştır. Ayrıca Tablo 4'de, etkin olmayan karar verme birimlerinin ne ölçüde etkinsiz olduğunu ve etkin olabilmesi için hangi etkin olan karar verme birimini, ne ölçüde refarans alacağı ile ilgili bilgilerde içermektedir. Örnek verilecek olursa, SARKY'in etkinlik skoru 0,62'dir. SARKY'nin etkin olabilmesi için, BURCE firmasını \%72, CELHA'y1 $\% 21$, CEMAS'1 \%4, ISDMR'yi \%3 oranında referans almalıdır. Aynı şekilde diğer etkin olmayan firmaların referans oranları verilmiştir.

Tablo 5'de firmaların girdi yönlü CCR modeline göre, etkinlik skorları ve değişkenlerin artık değerleri verilmiştir.

Tablo 5: 2018 yılı BIST 100 de yer alan Ana Metal Sanayi Firmalarının CCR girdi yönlü etkinlik skoru ve değişkenlerin artık değerleri

\begin{tabular}{|l|l|r|r|r|r|r|r|r|r|}
\hline DMU & Score & \multicolumn{1}{c}{ CO } & LO & TBOZ & TAKT & NKM & OKK & NGA & Tobin Q \\
\hline BRSAN & $87,14 \%$ & 0,00 & 0,07 & 0,00 & 90,62 & 0,00 & 32,89 & 74,03 & 0,26 \\
\hline BURCE & $\mathbf{1 0 0 , 0 0 \%}$ & & & & & & & & \\
\hline BURVA & $\mathbf{1 0 0 , 0 0 \%}$ & & & & & & & & \\
\hline CELHA & $94,02 \%$ & 0,00 & 0,06 & 0,00 & 43,81 & 0,00 & 1,17 & 86,87 & 0,00 \\
\hline CEMAS & $100,00 \%$ & & & & & & & & \\
\hline CEMTS & $100,00 \%$ & & & & & & & & \\
\hline CUSAN & $84,46 \%$ & 0,00 & 0,14 & 0,00 & 60,84 & 0,80 & 0,20 & 0,12 & 0,00 \\
\hline DMSAS & $91,48 \%$ & 0,00 & 0,42 & 0,00 & 34,69 & 0,00 & 0,57 & 59,28 & 0,15 \\
\hline DOKTA & $\mathbf{1 0 0 , 0 0 \%}$ & & & & & & & & \\
\hline ERBOS & $\mathbf{1 0 0 , 0 0 \%}$ & & & & & & & & \\
\hline EREGL & $\mathbf{1 0 0 , 0 0 \%}$ & & & & & & & & \\
\hline ISDMR & $\mathbf{1 0 0 , 0 0 \%}$ & & & & & & & & \\
\hline IZMDC & $84,66 \%$ & 0,26 & 0,00 & 0,00 & 95,90 & 11,75 & 0,75 & 60,96 & 0,00 \\
\hline OZBAL & $\mathbf{1 0 0 , 0 0 \%}$ & & & & & & & & \\
\hline SARKY & $\mathbf{6 2 , 4 1 \%}$ & 0,00 & 0,13 & 0,00 & 31,09 & 0,00 & 0,93 & 78,88 & 0,00 \\
\hline TUCLK & $83,99 \%$ & 0,00 & 0,38 & 0,00 & 62,84 & 4,03 & 0,66 & 15,10 & 0,00 \\
\hline
\end{tabular}

Etkinlik değeri 0,62 olan SARKY için değişkenler bazında yorumlama yapılacak olursa, girdi değişkenlerinden Likit Oranı değerini 1 birim azaltmalı ve Toplam aktiflerini 31,09 birim azaltmalıdır. Çıktı değişkenlerinden ise, Özkaynak Karlılığını 1 birim artırmalı, Net Gelirini 78,88 birim ve Tobin Q değerini de 1 birim artırmalıdır. Benzer yorumlar diğer etkin olmayan firmalar için yapılabilir.

Tablo 4 ve 5'deki Girdi yönlü CCR modelleri ölçeğe göre sabit getiri altında firmaların teknik etkinlik değerlerini bulmuştur. Girdi yönlü BCC modeli ile ölçeğe göre değişken getiri altında model çözüldüğünde aşağıdaki sonuçlar elde edilir.

Tablo 6'da Girdi yönlü BCC modeline göre etkin olan firmalara ait etkinlik değerleri verilmiştir. 
Tablo 6: 2018 yılı BIST 100 de yer alan Ana Metal Sanayi Firmalarının Girdi Yönlü BCC model etkinlik skorları

\begin{tabular}{|l|l|l|l|}
\hline KVB & Score & Benchmarks & Görülme Sıklığı \\
\hline BRSAN & $87,70 \%$ & $2(0,55) 4(0,29) 11(0,02) 12(0,13)$ & \\
\hline BURCE & $100,00 \%$ & & 4 \\
\hline BURVA & $100,00 \%$ & & \\
\hline CELHA & $100,00 \%$ & & 2 \\
\hline CEMAS & $100,00 \%$ & & 1 \\
\hline CEMTS & $100,00 \%$ & & 1 \\
\hline CUSAN & $89,89 \%$ & $2(0,63) 10(0,37)$ & \\
\hline DMSAS & $100,00 \%$ & & 1 \\
\hline DOKTA & $100,00 \%$ & & 1 \\
\hline ERBOS & $100,00 \%$ & & 1 \\
\hline EREGL & $100,00 \%$ & & 2 \\
\hline ISDMR & $100,00 \%$ & & 4 \\
\hline IZMDC & $95,79 \%$ & $9(099) 11(0,01)$ & \\
\hline OZBAL & $100,00 \%$ & & \\
\hline SARKY & $62,45 \%$ & $2(0,71) 4(0,21) 5(0,04) 8(0,01) 12(0,03)$ & \\
\hline TUCLK & $87,72 \%$ & $2(0,94) 6(0,06)$ & \\
\hline
\end{tabular}

Tablo 6' da etkin olan karar birimleri, BURCE, BURVA, CELHA, CEMAS, CEMTS, DMSAS, DOKTA, ERBOS, EREGL, ISDMR ve OZBAL'dır. BURCE ve ISDMR diğer

firmalar tarafindan $4 \mathrm{kez}$, CELHA ve EREGL $2 \mathrm{kez}$, CEMAS, CEMTS, DMSAS, DOKTA ve ERBOS $1 \mathrm{kez}$ referans gösterilmiştir. Ayrıca Tablo 8'de, etkin olmayan karar verme birimlerinin ne ölçüde etkinsiz olduğunu ve etkin olabilmesi için hangi etkin olan karar verme birimini, ne ölçüde referans alacağı ile ilgili bilgilerde içermektedir. Örnek verilecek olursa, SARKY'in etkinlik sokoru, 0,63' dür. Etkin olabilmesi için, BURCE firmasını \%71, CELHA'y1 \% 21, CEMAS' $1 \% 4$, DMSAS' $1 \% 1$ ve ISDMR'yi $\% 3$ oranında referans almalidır. $\mathrm{Bu}$ sonuçlar CCR modeli ile aynı çıkmıştır. Aynı şekilde diğer etkin olmayan firmaların referans oranları verilmiştir.

Tablo 7'de firmaların girdi yönlü BCC modeline göre, etkinlik skorları ve değişkenlerin artık değerleri verilmiştir. 
Tablo 7: 2018 yılı BIST 100 Ana Metal Sanayi Firmaları BCC girdi yönlü etkinlik skoru ve değişkenlerin artık değerleri

\begin{tabular}{|l|l|r|r|r|r|r|r|r|r|}
\hline KVB & Score & CO & LO & TBOZ & TAKT & NKM & OKK & NGA & Tobin Q \\
\hline BRSAN & $87,70 \%$ & 0,00 & 0,14 & 0,00 & 96,64 & 0,00 & 0,60 & 28,97 & 0,29 \\
\hline BURCE & $100,00 \%$ & & & & & & & & \\
\hline BURVA & $100,00 \%$ & & & & & & & & \\
\hline CELHA & $100,00 \%$ & & & & & & & & \\
\hline CEMAS & $100,00 \%$ & & & & & & & & \\
\hline CEMTS & $100,00 \%$ & & & & & & & & \\
\hline CUSAN & $89,89 \%$ & 0,00 & 0,02 & 0,00 & 07,82 & 5,14 & 0,19 & 20,22 & 0,00 \\
\hline DMSAS & $100,00 \%$ & & & & & & & & \\
\hline DOKTA & $100,00 \%$ & & & & & & & & \\
\hline ERBOS & $100,00 \%$ & & & & & & & & \\
\hline EREGL & $100,00 \%$ & & & & & & & & \\
\hline ISDMR & $100,00 \%$ & & & & & & & & \\
\hline IZMDC & $95,79 \%$ & 0,28 & 0,00 & 25,01 & 83,12 & 15,97 & 0,03 & 05,37 & 0,18 \\
\hline OZBAL & $100,00 \%$ & & & & & & & & \\
\hline SARKY & $62,45 \%$ & 0,00 & 0,12 & 0,00 & 21,79 & 0,00 & 0,06 & 89,89 & 0,00 \\
\hline TUCLK & $87,72 \%$ & 0,00 & 0,40 & 0,00 & 16,94 & 5,45 & 0,01 & 28,41 & 0,05 \\
\hline
\end{tabular}

Etkinlik değeri 0,62 olan SARKY için değişkenler bazında yorumlama yapılacak olursa, girdi değişkenlerinden Likit Oranı değerini 1 birim azaltmalı, Toplam aktiflerini 21,79 birim azaltmalıdır. Çıktı değişkenlerini ise, Özkaynak Karlılığını 1 birim artırmalı, Net Gelirini 89,89 birim artırmalıdır. Benzer yorumlar diğer etkin olmayan firmalar için yapılabilir.

Herhangi bir karar verme birimi için, $\Theta^{*}$ CR, girdi yönlü Charnes Cooper Rhodes modelinde bulunan teknik etkinlik ve $\Theta^{*}{ }_{\text {BCC }}$, girdi yönlü Banker Charnes Cooper modelinde bulunan teknik etkinlik değeri olmak üzere,

$$
\Theta^{*}{ }_{\text {ВСC }} \geq \Theta^{*}{ }_{\text {BCC }}
$$

Kısıtı her zaman doğrudur. Buradan, CCR girdi yönlü modeliyle etkin bulunan herhangi bir karar verme biriminin, BCC girdi yönlü modeliyle de mutlaka etkin bulunacağı söylenebilir. Ancak tersi doğru değildir (Sarı,2015). Yapılan çalışmada, CCR modeliyle etkin bulunan karar verme birimlerinin $\mathrm{BCC}$ modelinde etkin olduğu gözlemlenmiştir.

Tüm yıllar için firmaların etkinlik skorları, referans sayıları ve artık değişkenlere göre yorumları benzer şekilde yapılabilir.

Grafik 1 ve Grafik 2'de, her bir firmanın 2010-2018 yılları arasındaki 8 yıllık ortalama performan değerlerini göstermektedir. Değerlere göre, SARKY, TUCLK, DOKTA, DMSAS ve CEMAS etkinliği düşük olan firmalardır. 
Grafik 1: 2010-2018 dönemi için firmaların girdi yönelimli BCC modelleri etkinlik skorları

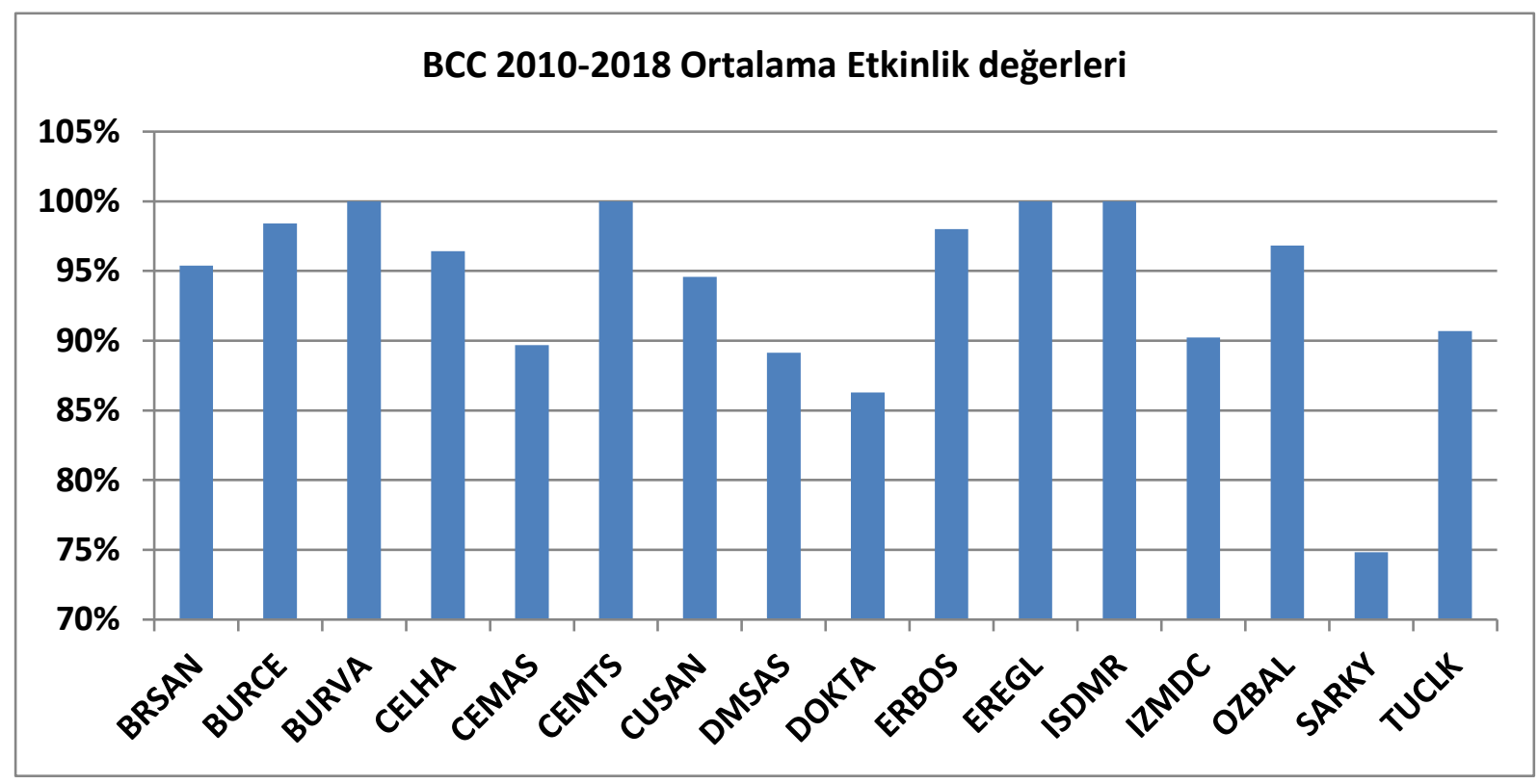

Grafik 2: 2010-2018 dönemi için firmaların girdi yönelimli CCR modelleri etkinlik skorları

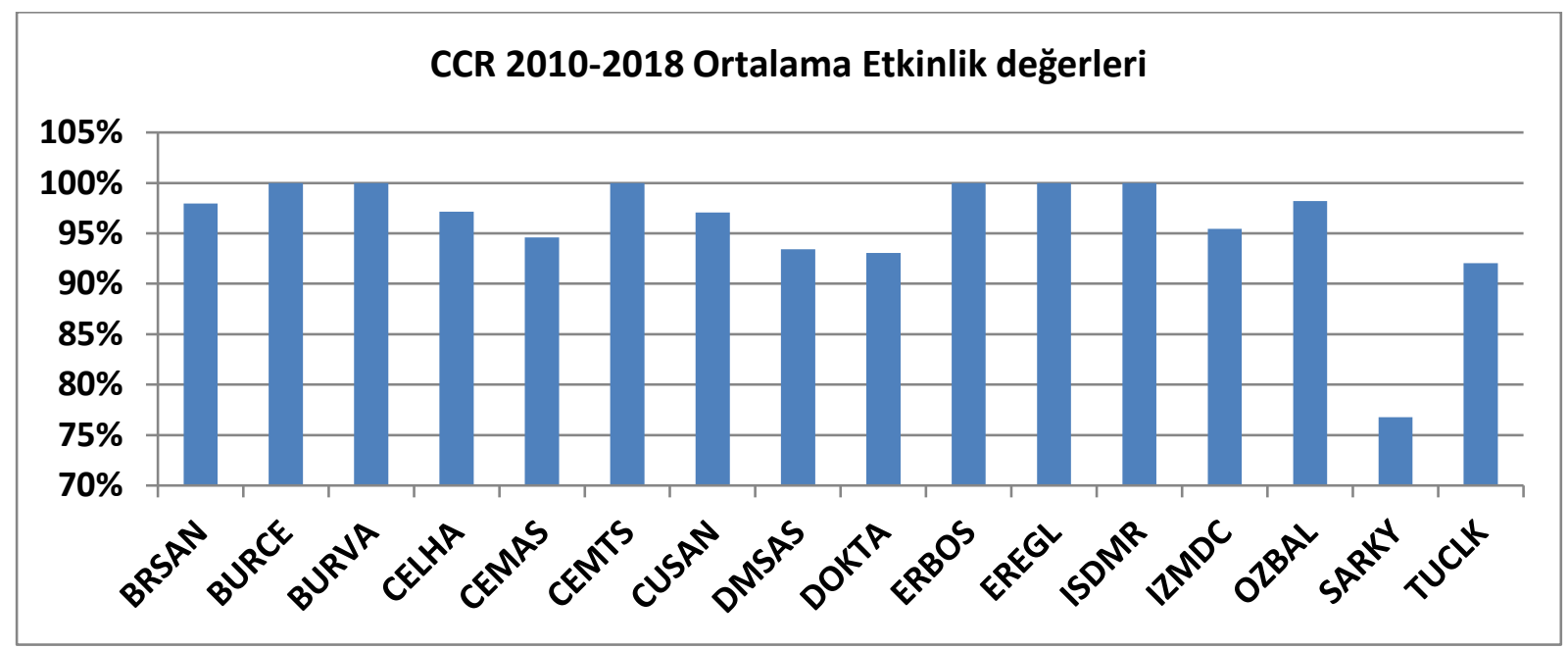

\section{SONUÇ}

Çalışmada, BIST'de yer alan ana metal sanayi firmaları, 2010-2018 yıllarında Finansal rasyo değerleri kullanılarak, Veri Zarflama Analizi yöntemi ile finansal performansları ölçülmüş ve firmaların yıllar bazında etkinlik analizi hesaplanmıştır. Çalışmada son yıl 2018 yılı verileri olduğundan, ana metal sanayi firmalarının 2018 yılı etkinlik değerleri, girdi ve çıktı değişkenlerinde yapılacak iyileştirmeler değerlendirilmiş, 2010-2018 dönemi için de etkinlik skorlarına göre grafiklerle sonuçlar tartışılmıştır. Girdi yönelimli CCR ve BCC modellerinin 2010-2018 yılları arasında ortalama etkinlik değerlerinin firmalar bazında benzer sonuçlar verdiği görülmüştür. Yapılan analizlerin tutarlı olduğu söylenebilir. Firmaların etkinlikleri yıllar bazında karşılaştırıldıklarında, her iki modelde de etkinliği en düşük olan firma, Sarkusyan Bakır A.Ş., takiben DOKTA, DMSAS, TUCLK ve CEMAS şeklinde devam ettiği görülmüştür. 2010-2018 döneminde etkinlik skorları, ilgili bütün firmaların yıllık ortalama 
değerleri; CCR ve BCC modeline göre 2012 yılından 2018 yılına kadar genel bir düşüş trendi göstermektedir. 2018 yılında 2016-2017 yıllarına göre bir parça pozitif yöne dönüş trendi göstermesine rağmen 2012 yılından daha düşük seviyede olduğu görülmüştür (Grafik 3-4).

Grafik 3: 2010-2018 dönemi boyunca İmalat Sanayi Firmalarının ortalama BCC etkinlik değerleri

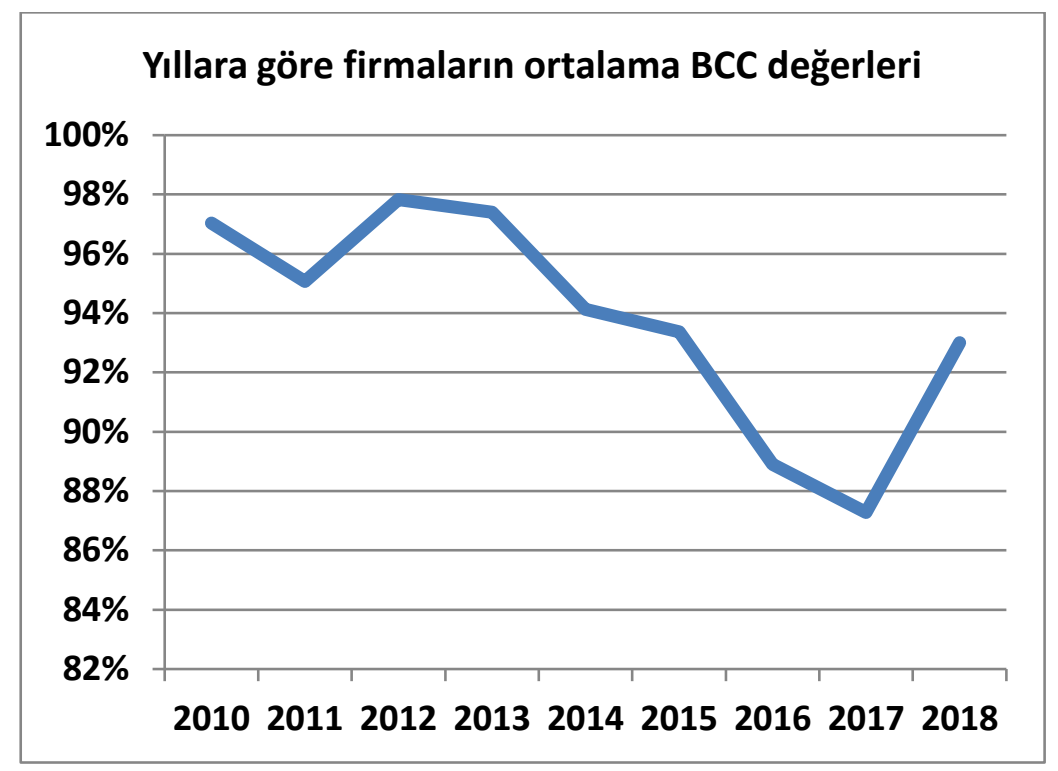

Grafik 4: 2010-2018 dönemi boyunca İmalat Sanayi Firmalarının ortalama CCR etkinlik değerleri

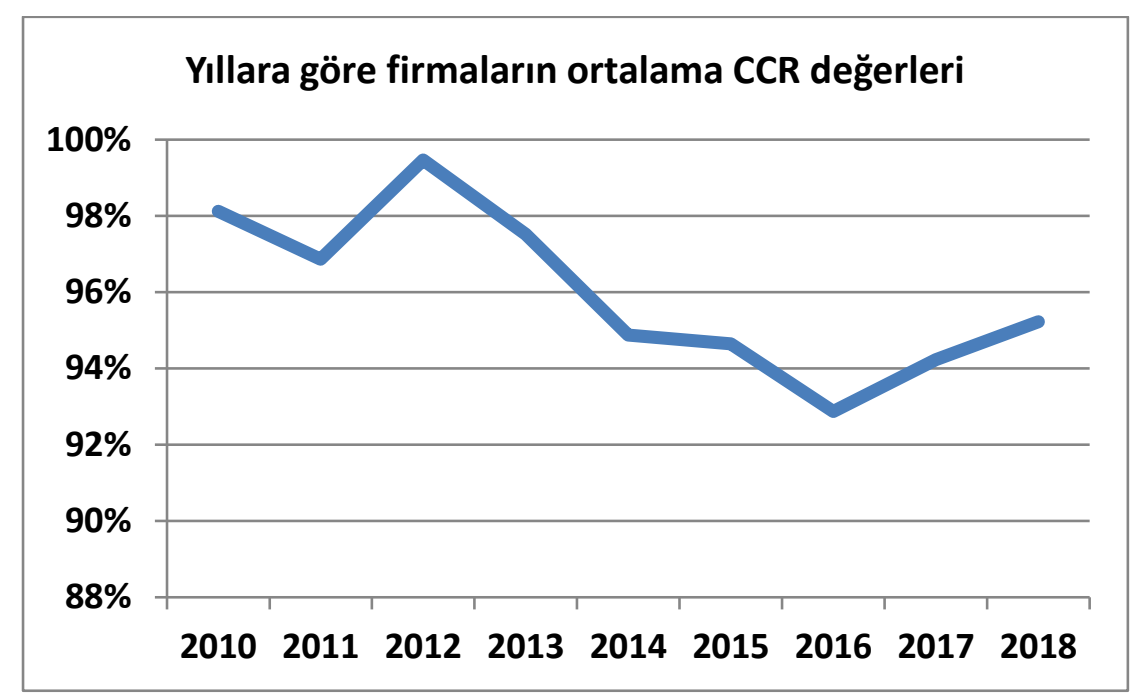

Çalışmada elde edilen etkinlik değerleri, görecelidir. Analiz için seçilen girdi-çıktının türü ve kullanılan yöntemle ilişkilidir. Bu nedenle bu sonuçlar, bazı çalışmalar ile benzer sonuçlar vermekle beraber bazı çalışmalara göre de bir miktar farklı sonuçlar vermektedir. VZA yöntemi ile ulaşılan sonuçları değerlendirirken dikkat edilmesi gereken husus, bu analizde elde edilen teknik etkinlik değerleri tahmin edilen birimlerin, gözlem kümesini oluşturan birimlere göre etkinliklerinin ölçülmüş olmasıdır. Bundan sonraki çalışmalarda, gelişmekte olan ülkeler ve gelişmiş ülkelerdeki ana metal firmalarına uygulanarak bu sektörlerin gelişmiş ve gelişmekte olan ülkelerde nasıl bir farklılığa sahip olduğu araştırılabilir. 


\section{KAYNAKÇA}

ALTIN, H., (2010). Küresel Kriz Ortamında İMKB Sınai Şirketlerine Yönelik Finansal Etkinlik Sınaması: Veri Zarflama Analizi Uygulaması", Anadolu Üniversitesi Sosyal Bilimler Dergisi, 10(2), 15-30.

ARIĞ, T.T., (2011). Etkinlik Hesaplama Yöntemi olarak Veri Zarflama Analizi ve IMKB'de İşlem gören İmalat Sanayi Şirketlerinin Göreli Finansal Etkinliklerinin Değerlendirilmesine İlişkin bir Uygulama, Yıldız Teknik Üniversitesi, $\quad$ Sosyal Bilimler Enstitüsü, İşletme Anabilim Dalı, YL tezi, İstanbul.

ASLAN, E., (2009), İMKB Metal Ana Endeksine Kote olan Şirketlerin Etkinliklerinin Veri Zarflama ile Analizi, Dokuz Eylül Üniversitesi Sosyal Bilimler Estitüsü, İşletme Anabilim Dalı, Sayısal Yöntemler ve Yönetim Bilimi YL Tezi, İzmir.

ATA, A. H. ve YAKUT, E., (2009). Finansal Performansa Dayalı Etkinlik Ölçümü: İmalat Sektörü Uygulaması, Kocaeli Üniversitesi Sosyal Bilimler Enstitüsü Dergisi, 18(2), 80 -100 .

BAKIRCI, F., ESLAMİAN SHİRAZ, S., ve SATTARY, A., (2014). BIST'de Demir, Çelik Metal Ana Sanayii Sektöründe Faaliyet Gösteren İşletmelerin Finansal Performans Analizi: VZA Süper Etkinlik ve TOPSIS Uygulaması, Ege Akademik Bakış,14(1),9-19.

CENGER, H., (2011). İMKB'de İşlem Gören Çimento Şirketlerinin Performanslarının Ölçülmesinde Veri Zarflama Analizi Yaklaşımı, Atatürk Üniversitesi İktisadi ve İdari Bilimler Dergisi, 25(3-4), 31-44.

CHARNES, A., COOPER W., ARIE Y., LEWIN SEIFOD L. M., (1994). Data Envelopment Analysis: Theory, Methodology and Applications, Kluwer Akademic Publishers, Boston.

COOPER, W.W., SEIFORD, L.M., Tone, K., (2000). Data Envelopment Analysis A Comprehensive Text with Models, Applications, References and DEA-Solver, Kluwer Academic Publishers, Dordrecht, 318p, 2000.

COOPER, WILLIAM W., SEIFORD, LAWRENCE M. and TONE, KAORU., (2007). Data Envelopment Analysis A Comprehensive Text With Models, Applications, References And DEA -Solver Software, Netherlands:Springer, Second Edition.

ÇITAK, L. ve İLTAŞ, Y., (2017). Ar-Ge Yatıımlarının Finansal Performans Üzerindeki Etkisi ve BIST teknoloji Endeksi Firmalarının Etkinliklerinin Değerlendirilmesi, Muhasebe ve Finansman Dergisi, Ekim-2017, 239-254

Demir çelik sektör raporu (2019), Sanayi ve teknoloji bakanliği Sanayi ve verimlilik genel müdürlüğü,

file://D:/Users/Downloads/Demir_Celik_Sektor_Raporu_2019\%20(1).pdf. Erişim Tarihi: 12/11/2019.

DESTAFANIS, S. ve SENA, V. (2007). Patterns of Corporate Governace and Techinical Efficiency in Italian Manufacturing, Published online in Winley InterScience, 28: $27-$ 40.

ERTUĞRUL İ. ve TUŞ IŞIK A. , (2008), İşletmelerin VZA ile Mali Tablolarına Dayalı etkinlik ölçümü: Metal Ana Sanayiinde bir Uygulama, Afyon Kocatepe Üniversitesi, İ.İ.B.F. Dergisi, X (I), 201-217. 
LIU, S.T. ve WANG, R.T., (2009). Efficiency measures of PCB manufacturing firms using relational two-stage data envelopment analysis, Experts Systems with Applications, 36: 4935-4939.

MAHADEVAN, R. (2002). A DEA Approach to Understanding the Productivity Growth of Malaysia's Manufacturing Industries, Asia Journal of Management, 19, 587-600.

ORÇUN, Ç., ÇIMMEN A., ve ŞAHIN, A., (2014). Şirket Etkinlikleri: İMKB 100 İmalat Sanayi Şirketleri Uygulaması, Dumlupınar Üniversitesi Sosyal Bilimler Dergisi, 39.

ÖZEK, P., (2015). İmalat Firmalarının Etkinlik Analizi, Gaziosmanpaşa Üniversitesi Sosyal Bilimler Araştırmaları Dergisi, 10(1), 185-201.

ÖZDEN, A. ve HAÇIKOĞLU M., (2017). Ana Metal Sanayi Sektörü, Ekonomik Araştırmalar Departmanı Raporu https://www.atbank.com.tr/documents/ANA\%20METAL\%20SANAYI\%20SEKTOR U_EYLUL\%202017.PDF, Erişim Tarihi: 17/11/2019.

ÖZKAN, M. Ve BİRCAN H., (2015). Suşehri Küçük Sanayi Sitesinde Faaliyette Bulunan Firmaların VZA Yöntemiyle Etkinlik Analizi, KMÜ Sosyal ve Ekonomik Araştırmalar Dergisi, 17(28), 27-34.

SARI, Z., (2015). Veri Zarflama Analizi ve Bir Uygulama, Yayımlanmamış Yüksek Lisans Tezi, Hacettepe Üniversitesi İstatistik Anabilim Dalı, Ankara.

TOSUNOĞLU, B. Ve UYSAL, M., (2012). İSO 500'de Yer Alan İmalat Sektöründeki Yabanc1 Sermaye Payına Sahip Şirketlerin Etkinliklerinin Veri Zarflama Analizi ile Ölçülmesi, Atatürk Üniversitesi İktisadi ve İdari Bilimler Dergisi, 26(3-4), 333-344.

TUTKAVUL., K., (2019). Malmquist Toplam Faktör Verimlilik Endeksini Kullanarak finansal etkinlik ve verimlilik Ölçümü: Borsa İstanbul Sinai Endeksi'nde Bir Uygulama, Verimlilik Dergisi, 2, 49-93.

YALAMA, A., ve SAYIM, M., (2008). Veri Zarflama Analizi ile İmalat Sektörünün Performans Değerlendirmesi, Dokuz Eylül Üniversitesi İktisadi ve İdari Bilimler Fakültesi Dergisi, 23(1), 89-107.

YAYAR, R., ve ÇOBAN, M.N., (2012). İSO 500 Firmalarının Etkinliklerinin Ölçülmesinde Veri Zarflama Analizi Yaklaşımı: Dokuma ve Giyim Eşya Sanayi, Niğde Üniversitesi İIBF Dergisi, 2012, 5(2), 165-180.

YEŞILYURT, C., (2003). Matematik Programlama Tabanlı Etkinlik Ölçüm Yöntemlerinden Veri Zarflama Analizi, Yayımlanmamış Doktora Tezi, Cumhuriyet Üniversitesi Sosyal Bilimler Enstitüsü), Sivas.

YILDIZ A. (2007). İmalat Sanayi Şirketlerinin Etkinliklerinin Ölçülmesi, Gazi Üniversitesi İktisadi ve İdari Bilimler Fakültesi Dergisi, 9(2), 91-103. 